\title{
Adjuvant Chemoradiotherapy Versus Radical Surgery After Transanal Endoscopic Microsurgery for Intermediate Pathological Risk Early Rectal Cancer: a Single Center Experience With Long-term Surveillance
}

\section{Yunhao Li}

Peking Union Medical College Hospital

Xiaoyuan Qiu

Peking Union Medical College Hospital

\section{Weikun Shi}

Peking Union Medical College Hospital

Guole Lin ( $\nabla$ linguole@126.com )

Peking Union Medical College Hospital https://orcid.org/0000-0001-6225-3028

\section{Research}

Keywords: Rectal cancer, Transanal Endoscopic Microsurgery, Quality of life, Adjuvant therapy

Posted Date: March 3rd, 2021

DOI: https://doi.org/10.21203/rs.3.rs-271072/v1

License: (9) This work is licensed under a Creative Commons Attribution 4.0 International License. Read Full License

Version of Record: A version of this preprint was published at Surgery on October 1st, 2021. See the published version at https://doi.org/10.1016/j.surg.2021.08.044. 


\section{Abstract}

\section{Background}

The choice of subsequent treatment for intermediate risk rectal tumors after Transanal endoscopic microsurgery (TEM) between adjuvant chemoradiotherapy and total mesorectal excision (TME) is controversial. The present study aimed to compare survival and functional outcome between these two strategies.

\section{Methods}

This retrospective study included intermediate risk early rectal cancer patients after TEM in our center between 2010 and 2017. Patients were divided into adjuvant treatment and TME groups. Intermediate risk was defined as PT1 with lymphovascular invasion, poor differentiation or large diameter $(3-5 \mathrm{~cm})$ or pT2 with small diameter(less than $3 \mathrm{~cm}$ ). The study was based on follow-up data on survival and results from distributed validated scales for functional outcome.

\section{Results}

Postoperative overall survival (OS) and disease-free survival (DFS) were comparable between groups ( $p=$ 0.619 and $p=0.712$ respectively). Pathological T stage was an independent risk factor for DFS (HR 3.09, $95 \% \mathrm{Cl} 1.66-4.18, p=0.044)$. Anorectal symptoms, such as buttock pain, was significantly prevalent in the TME group $(p=0.030)$. TME group presented with poorer bowel function, including stool urgency ( $p<$ $0.001)$, bowel frequency $(p=0.016)$, severity of LARS $(p=0.039)$ and total LARS score $(p=0.040)$. Except for a lower score of vaginal lubrication in TME group than the adjuvant treatment group, sexual function was similar between the groups.

\section{Conclusion}

Like TME, adjuvant chemoradiotherapy is an alternative option for intermediate risk early rectal cancer after TEM and is associated with similar survival outcomes and better bowel function.

\section{Background}

Because of the widespread popularization of colonoscopy and other screening methods, the overall incidence of rectal cancer has exhibited a dramatically increase in recent years [1, 2-4]. Total mesorectal excision (TME) has remained the gold-standard for the treatment of rectal cancer without metastases since it was proposed by professor Heald in 1982 [5]. Radical TME surgery, primarily including low anterior resection (LAR) and abdominoperineal resection (APR), was adopted for over 30 years [6]. Investigations of oncologists validated that early stage rectal cancer, especially T1 rectal cancer without risk factors for recurrence and metastases (i.e., low differentiated and lymphatic or vascular invasion) may be treated via local excision with the absence of radical TME [7-9]. Transanal endoscopic microsurgery (TEM), which was invented by Dr. Buess in 1983, was put into constant use for the 
treatment of rectal carcinoma over years of practice [8-10]. The full-thickness resection makes it an advisable approach for low-risk early rectal cancer, according to several guidelines [9, 11-14]. Despite of the advantages, the deficiency of resecting lymph nodes in TEM resection remains highly controversial. Patients with poor histological characteristics hinder its application in clinical practice. Patients with pT1 or pT2 stage rectal cancer with high risk factors after TEM are highly recommended to undergo radical resection to lower the recurrence risk and improve survival outcome [15-16]. However, patients with intermediate risk of local recurrence and lymph node metastases after TEM occupy over half of locally resectable rectal cancer patients, which create a dilemma for treatment options between adjuvant chemoradiotherapy (CRT) and radical surgery [17]. TME may include lymph node dissection, but it is accompanied with a higher morbidity rate. CRT is beneficial for health-related quality of life (HRQoL) because of organ preservation, but it is inferior to radical surgery because of the absence of lymph node dissection. An increasing number of studies reported high morbidity and HRQoL problems caused by radical surgeries $[16,18-20]$.

The present study primarily compared oncological and functional outcomes between TME and adjuvant CRT in patients who were diagnosed with early rectal cancer with intermediate risk after primary TEM resection at our hospital.

\section{Methods}

\section{Patients and study design}

A retrospective study was performed based on the constructed database at Peking Union Medical College Hospital (PUMCH), Department of General Surgery. TEM has been adopted for treating early rectal cancer for one decade in PUMCH. Surgeons in our unit have accumulated abundant clinical experience, and patients' intact pathological and clinical information were available in the specific database created in our clinical center.

The present study involved patients who underwent TEM in our clinical center and were diagnosed with intermediate risk early rectal cancer via pathological examination, in accordance with relevant guidelines, between January 2010 and December 2017. Intermediate risk early rectal cancer was defined as a patient with one of the following properties: (1) pT1: Diameter range from 3 to $5 \mathrm{~cm}$ or $<3 \mathrm{~cm}$ but accompanied with at least one risk factor, including lymphatic and/or venous invasion and/or neural invasion and/or poor differentiation; or (2) pT2: Diameter less than $3 \mathrm{~cm}$ with the absence of any risk factors. For large benign lesions with small invasive component, tumor size was considered to be the maximum diameter of malignant tissue during pathological examination. Before the TEM procedure, all patients underwent pelvic MRI to exclude nodal metastases and preoperative colonoscopy to obtain biopsy results to satisfy the indications for surgery. Patients who met the following criteria were excluded from the study: (1) unable to give consent due to dementia; (2) barrier in comprehension of the questionnaire provided; (3) failed to return questionnaires by the cutoff date; and (4) diagnosed with malignant rectal neoplasms other than adenocarcinomas. All patients in our clinical center diagnosed with intermediate risk pT1 or 
pT2 rectal cancer were recommended to receive the following treatment, including adjuvant CRT or radical surgery. Patients bearing intermediate risk rectal cancer who underwent adjuvant therapy after TEM were in a follow-up that included more intense postoperative examinations.

Patients meeting the selection criteria were grouped into the TME group (including LAR and APR) or adjuvant treatment group. Oncological outcome was acquired from telephone interviews and outpatient follow-up records. Functional outcome was primarily obtained from distributed paper questionnaires, online fillings and telephone follow-up. The European Organization for Research and Treatment of Cancer Quality of Life colorectal cancer specific module (EORTC-QLQ-CR29) was used to obtain an overall impression of a patient's HRQoL. Low anterior resection syndrome (LARS) score and Wexner score were used as scales to assess patients' defecatory or anorectal function. The Female Sexual Function Index (FSFI) and five items version of the International Index of Erectile Function (IIEF-5) were used to evaluate female and male postoperative sexual function, respectively. To avoid bias from potential confounding variables, we used the Propensity Score match $(P S M)$ method (match tolerance $=0.05)$. Enrolled patients had an average 42.63 months of follow-up (range $12-73$ months).

\section{Radical surgery}

Specimens resected during TEM were reviewed by experienced pathologists and diagnosed as intermediate risk pT1 or pT2 rectal cancer. Patients underwent radical surgeries 4 - 8 weeks after primary TEM. The choice of surgical technique between LAR and APR were primarily determined by the distance from the anal verge. All patients were informed of the possibility and inconvenience created by a permanent stoma. The anastomosis method involved stapling and hand sewing. Surgeons assessed the suitable time for diverse stoma if it was suitable. Patients received a contrast enema and abdominal CT scan before the reversal to certify the continuity and liquidity of the distal digestive tract and exclude probable distant metastasis. Patients who had lymph node metastasis on pathological examination after TME were recommended for subsequent adjuvant therapy.

\section{Adjuvant treatment}

Postoperative CRT included concurrent chemoradiotherapy (CCRT) and radiotherapy alone. Patients who received CCRT had a long course of radiotherapy with the chemotherapeutics. Chemotherapy regimen primarily included single-agent capecitabine, oxaliplatin plus intravenous 5-Fu/LV (FOLFOX) or oxaliplatin combined with capecitabine (XELOX). The choice of regimen was determined based on the oncologist's judgment.

\section{Oncological outcome}

Patients' oncological prognoses were assessed using overall survival (OS) and disease-free survival (DFS). The interval of OS was the time between the primary surgery and the date of death. The DFS interval was calculated as the interval between the primary surgery and recurrence date. Recurrence was 
primarily confirmed via biopsy during follow-up colonoscopy, and death information was certified via telephone interviews.

\section{Functional outcomes}

The following questionnaires were distributed after radical surgery or the eventual course of adjuvant treatment. For patients who received LAR with diverting ileostomy, the questionnaires were distributed after the reversal of stoma. For patients who underwent APR or LAR without diverting ileostomy, the questionnaires were sent after primary radical surgeries. Since patients in the adjuvant therapy group did not have stoma, the items related to stoma care was not listed in the distributed modules.

EORTC QLQ-CR29

EORTC QLQ-CR29 is a specific module of conventional EORTC QLQ-C30 for colorectal cancer patients, and it consists roughly of 4 main scales and 18 diverse single items [21]. All items are divided into functioning scales and symptom scales. Answers were graded as the extent of severity from 1 (not at all) to 4 (very much) and from 1 (very poor) to 7 (excellent) for items about HRQoL. The initially calculated scores were transformed into scales of $0-100$ according to a previously reported standard procedure [22].

\section{LARS score and Wexner score}

These two scales were used primarily to evaluate defecation problems. The LARS score has 5 questions on bowel movement-related disability, such as control of flatus, feces and liquid stool. The total LARS score ranges from 0 to 42 . Patient scores of 0 to 20,21 to 29 and 30 to 42 were categorized as no LARS, minor LARS and major LARS, respectively [23]. The Wexner score includes 5 questions on the frequency of solid and liquid stool, gas incontinence and the frequency of using a pad due to fecal incontinence. The overall Wexner score ranged from 0 to 20 , and a higher score indicates greater severity of fecal incontinence [24].

\section{FSFI and IIEF-5}

HRQoL problems related to sexual dysfunction were evaluated using the FSFI for female patients and the IIEF-5 for male patients. FSFI is a self-report scale that includes 6 domains (desire, arousal, lubrication, orgasm, satisfaction and pain). The separate scores for each domain are calculated as a total score [25]. IIEF- 5 consists of 5 questions about male erectile function. The severity of erectile dysfunction (ED) was categorized as severe ( 5 to 7 ), moderate ( 8 to 11 ), mild to moderate (12 to 16 ), mild (17 to 21 ) and no dysfunction [26].

\section{Statistical analysis}

Continuous variables are presented as the means (range) or proportions as necessary. Differences in continuous variables, such as median LARS score, were examined using the Mann-Whitney U test. 
Categorical variables in this study were assessed using Pearson's chi-squared test or Fisher's exact test (if applicable). Criteria for significant differences was a $p$ value $<0.050$. A $p$ value $<0.001$ was defined as an extremely distinct difference. The Kaplan-Meier method was used to compare OS and DFS. The log-rank test was used to distinguish differences in oncological outcome. Statistical analyses were performed using SPSS version 24.0 for Windows (SPSS Inc., Chicago, IL, USA).

\section{Results}

\section{Patients' Characteristics}

Of the 153 patients who met the inclusive criteria, 10 patients in the adjuvant treatment group and 13 patients in the TME group were excluded due to various factors, including barrier in the comprehension of the scales provided $(n=12)$, dementia or other diseases prevented consent $(n=3)$, and functional outcome scales feedback missing $(n=8)$. The remaining 130 patients were enrolled and matched one-toone using the nearest neighbor method. Tumor diameter, tumor height, cT classification, pT classification and age were considered. The proper math tolerance was calculated as 0.05 in propensity score matching, which resulted in 110 patients included in the study ( $n=55$ for each group). The entire inclusion and exclusion flow chart is shown in Figure 1. Patients' demographic, tumor characteristics and treatment details are listed in Table 1.

\section{Oncological outcome}

Of the 110 enrolled patients, 12 patients (10.91\%) developed recurrence after initial TEM surgery, including 8 patients $(7.27 \%)$ of local recurrence and 4 patients $(3.64 \%)$ of distant recurrence (Table 2 ). The local recurrence rate of patients undergoing adjuvant treatment was higher than patients who underwent TME $(9.09 \%$ vs. $5.45 \%)$, but this difference was not significant $(p=0.463)$. Four patients suffered distant metastases, with 2 patients in each group. The average interval from primary TEM surgery was 34.25 (24 - 79) months. The distant metastasis sites primarily included liver, lung, bone and distant lymph nodes. The Kaplan-Meier survival curve showed no significant differences in 5-year OS and DFS between the two treatments after primary TEM for intermediate risk early rectal cancer patients (Figure $2 \mathrm{a}$ and $2 \mathrm{~b}$ ).

The univariable analysis revealed that pT2, large tumor diameter, positive lymphovascular invasion and poor differentiation were the risk factors predicting recurrence (Table 3 ). The subsequent multivariable analysis indicated that only pT2 was an independent risk factor for DFS (HR 3.09, 95\% Cl 1.66-4.18, $p=$ 0.044) (Figure 2c).

\section{Functional outcomes}

The study reclaimed 105 effective questionnaires (excluding patients lost to follow up and death), including 52 (94.5\%) from the adjuvant treatment group and 53 (96.4\%) from the TME group.

\section{EORTC QLQ-CR29}


Compared with patients in the adjuvant treatment group, patients who underwent TME suffered from buttock pain more seriously ( 17.99 vs. $4.67, p=0.030)$. The adjuvant treatment group complained more about taste problems (7.91 vs. $1.73, p<0.001)$. Other functional and symptoms scales, including body image and sexual interest, were similar between the two groups without significant differences (Table 4).

\section{LARS score and Wexner score}

Patients' LARS and Wexner scores are shown in Table 5. The anorectal function in both groups was comparable before TEM. The TME group had a higher frequency of bowel urgency $(p<0.001)$. Categorization of the severity of LARS in the two groups and median total LARS scores also showed significant differences ( $p=0.039$ and 0.040 , respectively). However, there was no significant difference between the 4 other domains of the LARS score related to flatus or liquid stool control between the two groups $(p>0.05)$. The results of Wexner scores between the two groups were not significantly different either $(p=0.173)$.

\section{FSFI and IIEF-5}

Based on the preoperative data, the sexual function of all enrolled patients was not different between the two groups. Lubrication disorder of the vaginal canal was significantly severe in female patients who underwent TME surgery ( 7.52 vs. $2.03, p<0.001)$, but other indexes of FSFI and total FSFI score were comparable to the adjuvant treatment group patients (Figure 3). Postoperative erectile function evaluation revealed that males in the radical TME group experienced a higher proportion of moderate and severe ED $(20.69 \%$ vs. $11.76 \%)$, but without a significant difference. Patients in both groups had a similar overall IIEF-5 score, which reflected parallel erectile function (Table 6).

\section{Discussion}

According to previous reports, approximately $75 \%$ of the patients who suffered recurrence after local excision of rectal cancer were intermediate risk pT1 or pT2 stage [27-28]. The choice between postoperative radical surgery and adjuvant treatment was always a barrier for surgeons and oncologists to implement the most appropriate treatment option. TEM is a relatively novel local excision surgical method to perform en-bloc resection through a specific working tunnel $[10,12,14]$. We performed this study to compare the oncological and functional outcomes in a series of intermediate-risk early rectal cancer patients who received adjuvant treatment or TME after TEM. Overall, each option had its pros and cons in different aspects.

Nearly $11 \%$ of the enrolled patients developed local or distant recurrence after initial TEM resection. The overall recurrence rate was consistent with previous reports [29]. The present study found no significant differences in 5-year OS and DFS between the different post-TEM treatment methods. Pathological T stage was a predisposing factor for recurrence. The present study found that although several pathological characteristics, such as tumor diameter and lymphovascular invasion, were high risk factors for a low DFS rate, only PT stage was an independent predicting factor for low DFS rate in multivariable 
analysis. This result suggests that patients who were diagnosed as pT2 after TEM should be in a closer out-patient follow-up regardless of post-TEM therapy. The results were in great accordance with a systematic review done by Cutting et al., which maintained that local excision plus adjuvant therapy should not be recommended for PT2 patients [30].

We clearly observed that patients who underwent TME suffered from a greater proportion of buttock pain, which is consistent with some related work on comparisons of local excision and TME. Taste complaint was more obvious in the adjuvant treatment group patients, but this finding may be somewhat explained by the chemotherapy module bias after TEM. No other symptom or functional scales showed significant differences. There is no denying that adjuvant treatment may produce a series of side effects, such as perforation, diarrhea or proctitis, especially in patients who choose radiotherapy [31-32]. Borstlap et al. and Smart et al. reported the complication rate ranged from approximately $6-52 \%[17,31]$. The 2 patients who underwent CCRT in our study reported no radiotherapy-related side effects. However, this result may not represent the low risk of side effects of adjuvant treatment due to the small sample size.

TEM is an advisable method for the treatment of early rectal cancer partially because of its unique transanal working pattern. Several studies demonstrated that TEM had little effect on patients' HRQoL after surgery. Biviano et al. enrolled 66 rectal cancer patients and concluded that TEM had no significant effect on anal function [33]. Perioperative damage to the anal sphincter caused by TME is consistently a concern for surgeons and patients. Anorectal function was evaluated using 2 validated questionnaires, and great disparity occurred between the groups. Patients in the TME group demonstrated worse bowel function, particularly bowel urgency and stool control. More patients in the TME group reported major LARS, which indicates a higher level of bowel dysfunction. These results corroborate the findings of many previous works. Chen et al. found that nearly half of the patients who underwent TME suffered from major LARS [34]. Bohlok et al. (2019) also showed that a large proportion (72.1\%) of patients after TME complained of LARS to different extents [35]. A meta-analysis done by Kidane et al. also proposed the viewpoint that TEM could be adopted as a reliable device which provides similar oncological control but lower mortality rate [36]. One unexpected finding was the extent to which the overall Wexner score between the 2 groups was not significantly different. This result may be partially due to the nonspecificity of the Wexner scale and distortion of the included questions, especially after filling out the LARS questionnaire. Cheong et al. performed a prospective observational study and revealed severe bowel dysfunction caused by anterior resection for rectal cancer. The dysfunction partially originated from the procedure of coloanal anastomosis [37]. Sclafani et al. concluded that CRT did not increase the significant detrimental effect on HRQoL and bowel function in rectal cancer patients [38]. Therefore, the potential benefit of adjuvant therapy in the lower rate of LARS should not be underestimated. The followup time was another vital factor for postoperative LARS based on some published reports. Therefore, our data should be interpreted with caution because the follow-up months for each patient were diverse [33, 39].

Latent damage to the pelvic nerve during TME is a controversial side-effect of postoperative sexual function preservation. Published reports on the differences in sexual function between adjuvant CRT and 
radical surgery were limited [40]. We employed different gender-specific scales for patients' sexual functions and clearly found no obvious differences between the treatment of options. Except for a higher score of vaginal lubrication in the adjuvant treatment group, no other scales in the FSFI were different between the two groups. Male patients' erectile function is a big concern for surgeons, but there was no significant difference on median overall IIEF- 5 score between the treatments. The ratio of moderate and severe ED patients was higher in the TME group than the adjuvant treatment group (20.69\% vs. $11.76 \%$ ), but no significant difference was found. These results may be biased to some extent due to the selfreported nature of the scales and the small number of patients who underwent adjuvant therapy when diagnosed with N2 stage after TME.

Our study has several limitations, such as its retrospective design and relatively short following-up period. Except for these points, the self-reported questionnaires we used in this study were more or less subjective. Some examinations, such as anal manometry, should be used to increase the objective evidence of bowel function. The same surgeon performed most of the TEM in our unit after standard training. However, the learning curve may also cause bias of the pathological results for the earliest cases.

\section{Conclusion}

All in all, compared with TME, adjuvant therapy poses a similar oncological outcome with no inferiority in postoperative overall or disease-free survival for intermediate risk early rectal cancer patients after primary TEM resection. Pathological T stage may be an independent risk factor for recurrence regardless of treatment. TEM with adjuvant therapy has less impact on patients' HRQoL with better bowel function and similar levels of sexual function.

\section{List Of Abbreviations}

Transanal endoscopic microsurgery (TEM); Total mesorectal excision (TME); Overall survival (OS) ;Disease-free survival (DFS); Low anterior resection (LAR) ; Abdominoperineal resection (APR) Chemoradiotherapy (CRT); Health-related quality of life (HRQoL); European Organization for Research and Treatment of Cancer Quality of Life colorectal cancer specific module (EORTC-QLQ-CR29); Female Sexual Function Index (FSFI); Five items version of the International Index of Erectile Function (IIEF-5); Concurrent chemoradiotherapy (CCRT); Erectile dysfunction (ED) Low anterior resection syndrome (LARS).

\section{Declarations}

\section{Ethics approval and consent to participate:}

Our protocol has been approved and got ethics approval and consent from the IRB of Peking Union Medical College Hospital (S-K1237). 


\section{Consent for publication:}

This article doesn't include any individual person's data.

\section{Availability of data and materials:}

The data that support the findings of this study are available on request from the corresponding author. The data are not publicly available due to their containing information $₫$ such as sex function that could compromise the privacy of research participants.

\section{Competing interests:}

All the authors declare that they have no conflict of interest.

\section{Funding information:}

This study is supported and funded by Beijing Major Science and Technology Projects, under Grant: No.D1711070026000.

\section{Authors' contributions:}

Yunhao Li.: Data curation, Writing- Original draft preparation. Xiaoyuan Qiu: Software, Validation. Weikun Shi: Writing, Reviewing and Editing. Guole Lin: Visualization, Investigation.

\section{Acknowledgements:}

This study is supported and funded by Beijing Major Science and Technology Projects. Fiancée of the first author, Miss Su also contributes a lot to the process of composition.

\section{References}

1. Rutten HJ, den Dulk M, Lemmens VE, van de Velde CJ, Marijnen CA. Controversies of total mesorectal excision for rectal cancer in elderly patients. Lancet Oncol. 2008; doi:10.1016/S14702045(08)70129-3

2. Radu I, Anitei G, Scripcariu V, Dragomir C. Rezecţia anterioară joasă de rect cu excizie totală de mezorect. Rezultate imediate [Low anterior resection of the rectum with total mesorectal excisionimmediate results]. Rev Med Chir Soc Med Nat lasi. 2011;115:460-465.

3. De Felice F, Crocetti D, Maiuri V, Parisi M, Marampon F, Izzo L, mfl. Locally Advanced Rectal Cancer: Treatment Approach in Elderly Patients. Curr Treat Options Oncol. 2020; doi: 10.1007/s11864-0190692-8.

4. Glynne-Jones R, Grainger J, Harrison M, Ostler P, Makris A. Neoadjuvant chemotherapy prior to preoperative chemoradiation or radiation in rectal cancer: should we be more cautious? $\mathrm{Br} \mathrm{J}$ Cancer. 2006; doi: 10.1038/sj.bjc.6602960. 
5. Heald RJ, Husband EM, Ryall RD. The mesorectum in rectal cancer surgery-the clue to pelvic recurrence? Br J Surg; 1982; doi: 10.1002/bjs.1800691019.

6. Di Fabio F, Koller M, Nascimbeni R, Talarico C, Salerni B. Long-term outcome after colorectal cancer resection. Patients' self-reported quality of life, sexual dysfunction and surgeons' awareness of patients' needs. Tumori. 2008;94:30-35.

7. Fenech DS, Takahashi T, Liu M, Spencer L, Swallow CJ, Cohen Z, mfl. Function and quality of life after transanal excision of rectal polyps and cancers. Dis Colon Rectum. 2007;50:598-603.

8. Stornes T, Wibe A, Nesbakken A, Myklebust TÅ, Endreseth BH. National Early Rectal Cancer Treatment Revisited. Dis Colon Rectum. 2016; doi: 10.1007/s10350-006-0865-y.

9. O'Neill CH, Platz J, Moore JS, Callas PW, Cataldo PA. Transanal Endoscopic Microsurgery for Early Rectal Cancer: A Single-Center Experience. Dis Colon Rectum. 2017; doi: 10.1097/DCR.0000000000000764.

10. Burghardt J, Buess G. Transanal endoscopic microsurgery (TEM): a new technique and development during a time period of 20 years. Surg Technol Int. 2005;14:131-137.

11. Langer $C$, Liersch T, Markus P, Süss M, Ghadimi M, Füzesi L, mfl. Transanal endoscopic microsurgery (TEM) for minimally invasive resection of rectal adenomas and "Low-risk" carcinomas (UT1, G1 - 2). Z Gastroenterol. 2002; doi: 10.1055/s-2002-20210.

12. Buess G. Review: transanal endoscopic microsurgery (TEM). J R Coll Surg Edinb. 1993;38:239-245.

13. Schäfer HH, Vivaldi C, Hölscher AH. Lokale Nachexzision nach endoskopischer R1/R2-Polypektomie von pT1-,low-risk"- Karzinomen des Rektums durch transanale endoskopische Mikrochirurgie (TEM) [Local excision with transanal endoscopic microsurgery (TEM) after endoscopic R1/R2-polypectomy of pT1 "low-risk" carcinomas of the rectum]. Z Gastroenterol. 2006; doi: 10.1055/s-2006-926877.

14. Borschitz T, Heintz A, Junginger T. The influence of histopathologic criteria on the long-term prognosis of locally excised pT1 rectal carcinomas: results of local excision (transanal endoscopic microsurgery) and immediate reoperation. Dis Colon Rectum. 2006; doi: 10.1007/s10350-006-05871.

15. Borschitz T, Heintz A, Junginger T. Transanal endoscopic microsurgical excision of pT2 rectal cancer: results and possible indications. Dis Colon Rectum. 2007; doi: 10.1007/s10350-006-0816-7.

16. Floyd ND, Saclarides TJ. Transanal endoscopic microsurgical resection of pT1 rectal tumors. Dis Colon Rectum. 2006; doi: 10.1007/s10350-005-0269-4.

17. Borstlap WA, Tanis PJ, Koedam TW, Marijnen CA, Cunningham C, Dekker E, mfl. A multi-centred randomised trial of radical surgery versus adjuvant chemoradiotherapy after local excision for early rectal cancer. BMC Cancer. 2016; doi: 10.1186/s12885-016-2557-x.

18. Bosch SL, Teerenstra S, de Wilt JH, Cunningham C, Nagtegaal ID. Predicting lymph node metastasis in PT1 colorectal cancer: a systematic review of risk factors providing rationale for therapy decisions. Endoscopy. 2013; doi: 10.1055/s-0033-1344238.

19. Okuyama T, Oya M, Ishikawa H. Budding as a risk factor for lymph node metastasis in $\mathrm{pT} 1$ or $\mathrm{pT} 2$ well-differentiated colorectal adenocarcinoma. Dis Colon Rectum. 2002; doi: 10.1007/s10350-004- 
6259-0.

20. Pai RK, Cheng YW, Jakubowski MA, Shadrach BL, Plesec TP, Pai RK. Colorectal carcinomas with submucosal invasion ( $\mathrm{pT} 1$ ): analysis of histopathological and molecular factors predicting lymph node metastasis. Mod Pathol. 2017; doi: 10.1038/modpathol.2016.166.

21. Gujral S, Conroy T, Fleissner C, Sezer O, King PM, Avery KN, mfl. European Organisation for Research and Treatment of Cancer Quality of Life Group. Assessing quality of life in patients with colorectal cancer: an update of the EORTC quality of life questionnaire. Eur J Cancer. 2007; doi: 10.1016/j.ejca.2007.04.005.

22. Whistance RN, Conroy T, Chie W, Costantini A, Sezer O, Koller M, mfl. European Organisation for the Research and Treatment of Cancer Quality of Life Group. Clinical and psychometric validation of the EORTC QLQ-CR29 questionnaire module to assess health-related quality of life in patients with colorectal cancer. Eur J Cancer. 2009; doi: 10.1016/j.ejca.2009.08.014.

23. Emmertsen KJ, Laurberg S. Low anterior resection syndrome score: development and validation of a symptom-based scoring system for bowel dysfunction after low anterior resection for rectal cancer. Ann Surg. 2012; doi: 10.1097/SLA.0b013e31824f1c21.

24. Kupsch J, Jackisch T, Matzel KE, Zimmer J, Schreiber A, Sims A, mfl. Outcome of bowel function following anterior resection for rectal cancer-an analysis using the low anterior resection syndrome (LARS) score. Int J Colorectal Dis. 2018; doi: 10.1007/s00384-018-3006-x.

25. Rosen R, Brown C, Heiman J, Leiblum S, Meston C, Shabsigh R, mfl. The Female Sexual Function Index (FSFI): a multidimensional self-report instrument for the assessment of female sexual function. J Sex Marital Ther. 2000; doi: 10.1080/009262300278597.

26. Neijenhuijs KI, Holtmaat K, Aaronson NK, Holzner B, Terwee CB, Cuijpers P, mfl. The International Index of Erectile Function (IIEF)-A Systematic Review of Measurement Properties. J Sex Med. 2019; doi: 10.1016/j.jsxm.2019.04.010.

27. Beaton C, Twine CP, Williams GL, Radcliffe AG. Systematic review and meta-analysis of histopathological factors influencing the risk of lymph node metastasis in early colorectal cancer. Colorectal Dis. 2013; doi: 10.1111/codi.12129.

28. Tateishi Y, Nakanishi Y, Taniguchi H, Shimoda T, Umemura S. Pathological prognostic factors predicting lymph node metastasis in submucosal invasive (T1) colorectal carcinoma. Mod Pathol. 2010; doi: 10.1038/modpathol.2010.88.

29. Lai IL, You JF, Chern YJ, Tsai WS, Chiang JM, Hsieh PS, mfl. Survival analysis of local excision vs total mesorectal excision for middle and low rectal cancer in pT1/pT2 stage and intermediate pathological risk. World J Surg Oncol. 2019; doi: 10.1186/s12957-019-1763-9.

30. Cutting JE, Hallam SE, Thomas MG, Messenger DE. A systematic review of local excision followed by adjuvant therapy in early rectal cancer: are pT1 tumours the limit? Colorectal Dis. 2018; doi: $10.1111 /$ codi. 14340 .

31. Smart CJ, Korsgen S, Hill J, Speake D, Levy B, Steward M, mfl. Multicentre study of short-course radiotherapy and transanal endoscopic microsurgery for early rectal cancer. Br J Surg. 2016; doi: 
10.1002/bjs. 10171.

32. Komori K, Kimura K, Kinoshita T, Sano T, Ito S, Abe T, mfl. Complications associated with postoperative adjuvant radiation therapy for advanced rectal cancer. Int Surg. 2014; doi: 10.9738/INTSURG-D-13-00200.1.

33. Biviano I, Balla A, Badiali D, Quaresima S, D'Ambrosio G, Lezoche E, mfl. Anal function after endoluminal locoregional resection by transanal endoscopic microsurgery and radiotherapy for rectal cancer. Colorectal Dis. 2017; doi: 10.1111/codi.13656.

34. Chen TY-T, Wiltink LM, Nout RA, Meershoek-Klein Kranenbarg E, Laurberg S, Marijnen CAM, m.fl. Bowel function 14 years after preoperative short-course radiotherapy and total mesorectal excision for rectal cancer: report of a multicenter randomized trial. Clin Colorectal Cancer. 2015; doi: 10.1016/j.clcc.2014.12.007.

35. Bohlok A, Mercier C, Bouazza F, Galdon MG, Moretti L, Donckier V, mfl. The burden of low anterior resection syndrome on quality of life in patients with mid or low rectal cancer. Support Care Cancer. 2020; doi: 10.1007/s00520-019-04901-2.

36. Kidane B, Chadi SA, Kanters S, Colquhoun PH, Ott MC. Local resection compared with radical resection in the treatment of T1N0M0 rectal adenocarcinoma: a systematic review and metaanalysis. Dis Colon Rectum. 2015; doi: 10.1097/DCR.0000000000000293.

37. Cheong C, Oh SY, Choi SJ, Suh KW. Ultralow Anterior Resection and Coloanal Anastomosis for LowLying Rectal Cancer: An Appraisal Based on Bowel Function. Dig Surg. 2019; doi: $10.1159 / 000490899$.

38. Sclafani F, Peckitt C, Cunningham D, Tait D, Giralt J, Glimelius B, mfl. Short- and Long-Term Quality of Life and Bowel Function in Patients With MRI-Defined, High-Risk, Locally Advanced Rectal Cancer Treated With an Intensified Neoadjuvant Strategy in the Randomized Phase 2 EXPERT-C Trial. Int J Radiat Oncol Biol Phys. 2015; doi: 10.1016/j.jjrobp.2015.03.038.

39. Wolff HA, Dröge LH. The EXPERT-C Trial Defines a Reference for Future Research: Quality of Life and Bowel Function in Patients With Locally Advanced Rectal Cancer Treated With Neoadjuvant Chemotherapy Followed by Chemoradiation Therapy Before Surgery. Int J Radiat Oncol Biol Phys. 2015; doi: 10.1016/j.jirobp.2015.06.033.

40. Pontallier A, Denost Q, Van Geluwe B, Adam JP, Celerier B, Rullier E. Potential sexual function improvement by using transanal mesorectal approach for laparoscopic low rectal cancer excision. Surg Endosc. 2016; doi: 10.1007/s00464-016-4833-x.

\section{Tables}

Table 1a Patients characteristics 


\begin{tabular}{|c|c|c|c|}
\hline Items & $\begin{array}{l}\text { Adjuvant treatment } \\
(\mathrm{n}=55)\end{array}$ & $\begin{array}{l}\text { TME } \\
(n=55)\end{array}$ & $p$ value \\
\hline Age, mean \pm SD & $60.27 \pm 3.125$ & $62.39 \pm 4.442$ & 0.531 \\
\hline $\mathrm{BMI}$, mean $\pm \mathrm{SD}\left(\mathrm{kg} / \mathrm{m}^{2}\right)$ & $25.67 \pm 4.679$ & $20.32 \pm 1.213$ & 0.147 \\
\hline CEA level (ng/mL) & $2.78 \pm 0.797$ & $2.92 \pm 1.013$ & 0.351 \\
\hline Gender & & & 0.175 \\
\hline Male & 29 & 36 & \\
\hline Female & 26 & 19 & \\
\hline Tumor height, mean \pm SD $(\mathrm{cm})$ & $6.59 \pm 0.639$ & $7.13 \pm 1.254$ & 0.256 \\
\hline Tumor diameter, mean \pm SD $(\mathrm{cm})$ & $2.57 \pm 0.263$ & $2.64 \pm 1.002$ & 0.198 \\
\hline ASA classification & & & 0.278 \\
\hline$\otimes$ & 21 & 27 & \\
\hline$\nabla$ & 32 & 24 & \\
\hline$\nabla$ & 2 & 4 & \\
\hline cT classification (pre-TEM) & & & 0.249 \\
\hline Tis & 21 & 27 & \\
\hline T1 & 34 & 28 & \\
\hline pT classification (post-TEM) & & & 0.634 \\
\hline T1 & 45 & 43 & \\
\hline T2 & 10 & 12 & \\
\hline Resection margin & & & 0.271 \\
\hline Ro & 53 & 49 & \\
\hline R1 & 2 & 6 & \\
\hline Distal margin, mean $\pm \mathrm{SD}(\mathrm{cm})$ & $1.11 \pm 0.375$ & $1.26 \pm 0.654$ & 0.885 \\
\hline Lymphovascular invasion† & 3 & 7 & 0.320 \\
\hline Differentiationt & & & 0.744 \\
\hline Well & 4 & 6 & \\
\hline Moderate & 28 & 25 & \\
\hline Poor & 23 & 24 & \\
\hline
\end{tabular}


$T M E$, total mesorectal excision; BMI, body mass index; $A S A$, American Society of Anesthesiologists score; TEM, Transanal Endoscopic Microsurgery.

† Evaluated by resected specimens after TEM

Table 1b Post-TEM treatment data 


\begin{tabular}{|c|c|c|c|}
\hline Items & $\begin{array}{l}\text { Adjuvant treatment } \\
(n=55)\end{array}$ & $\begin{array}{l}\text { TME } \\
(n=55)\end{array}$ & $p$ value \\
\hline TME categorizations, n (\%) & & & - \\
\hline LAR & - & $50(90.9)$ & \\
\hline APR & - & $5(9.1)$ & \\
\hline Type of anastomosis, n (\%) & & & - \\
\hline Handsewn & - & $4(8)$ & \\
\hline Stapled & - & $46(92)$ & \\
\hline Anastomotic height, mean \pm SD $(\mathrm{cm})$ & - & $4.02 \pm 1.127$ & - \\
\hline Type of approach, n (\%) & & & - \\
\hline Open & - & $6(10.9)$ & \\
\hline Laparoscopy & - & $49(89.1)$ & \\
\hline Diversion stoma, n (\%) & & $43(78.2)$ & - \\
\hline Grading of TME specimen, $\mathrm{n}(\%)$ & & & - \\
\hline Complete & - & $51(92.7)$ & \\
\hline Nearly complete & - & $3(5.5)$ & \\
\hline Incomplete & - & $1(1.8)$ & \\
\hline CRM involvement, n (\%) & & $1(1.8)$ & - \\
\hline Pathologic $\mathrm{N}$ classification (post-TME) & - & & - \\
\hline NO & - & 50 & \\
\hline N1 & - & 3 & \\
\hline N2 & - & 1 & \\
\hline Adjuvant therapy & & & $<0.001$ \\
\hline CCRT(Single-agent capecitabin) & 26 & 0 & \\
\hline CCRT(FOLFOX4) & 9 & 1 & \\
\hline CCRT(XELOX) & 20 & 1 & \\
\hline Radiotherapy alone & 0 & 2 & \\
\hline
\end{tabular}

$T M E$, total mesorectal excision; TEM, Transanl Endoscopic Microsurery. Abdominoperineal resection; LAR, Low anterior resection; CRM, Circumferential Resection Margin; FOLFOX4, Oxaliplatin + 5-FU + LV; XELOX, 
Oxaliplatin + Capecitabine; CCRT, concurrent chemoradiation therapy.

Table 2 Recurrence data after post-TEM treatment

\begin{tabular}{|lllll|}
\hline Items & $\begin{array}{l}\text { Total } \\
(\mathrm{n}=110)\end{array}$ & $\begin{array}{l}\text { Adjuvant } \\
\text { treatment } \\
(\mathrm{n}=55)\end{array}$ & $\begin{array}{l}\text { TME } \\
(\mathrm{n}=55)\end{array}$ & $\begin{array}{c}p \\
\text { value }\end{array}$ \\
\hline Overall rate of recurrence, $\mathrm{n}(\%)$ & $12(10.91)$ & $7(12.73)$ & $5(9.09)$ & 0.541 \\
\hline $\begin{array}{l}\text { Time interval from primary TEM } \\
\text { (months) }\end{array}$ & $28.32 \pm 6.220$ & $25.67 \pm 4.281$ & $32.33 \pm 5.597$ & 0.623 \\
\hline \begin{tabular}{l} 
Local recurrence, $\mathrm{n}(\%)$ \\
\hline $\begin{array}{l}\text { Time interval from primary TEM } \\
\text { (months) }\end{array}$
\end{tabular} & $8(7.27)$ & $5(9.09)$ & $3(5.45)$ & 0.463 \\
\hline Distant recurrence, $\mathrm{n}(\%)$ & $27.66 \pm 4.975$ & $23.52 \pm 3.227$ & $30.18 \pm 5.421$ & 0.318 \\
\hline Liver & $4(3.64)$ & $2(3.64)$ & $2(3.64)$ & 1.000 \\
\hline Lung & 1 & 0 & 1 & \\
\hline Bone & 1 & 1 & 0 & \\
\hline Distant Lymph node & 1 & 1 & 0 & 1 \\
\hline $\begin{array}{l}\text { Time interval from primary TEM } \\
\text { (months) }\end{array}$ & 1 & 0 & $37.23 \pm 2.982$ & 0.213 \\
\hline
\end{tabular}

TME, total mesorectal excision; TEM, Transanal Endoscopic Microsurgery

Table 3 Univariable and multivariable Cox regression analysis for disease-free survival 


\begin{tabular}{|c|c|c|c|c|}
\hline & \multicolumn{2}{|l|}{ Univariable analysis } & \multicolumn{2}{|c|}{ Multivariable analysis $\dagger$} \\
\hline & $\mathrm{HR}(95 \% \mathrm{Cl})$ & & $\mathrm{HR}(95 \% \mathrm{Cl})$ & $p$ value \\
\hline Age(years)‡ & $1.05(0.99-1.13)$ & 0.482 & & \\
\hline \multicolumn{5}{|l|}{ Gender } \\
\hline Male & 1.00 (reference) & & & \\
\hline Female & $1.32(0.84-1.93)$ & 0.250 & & \\
\hline \multicolumn{5}{|l|}{ pT classification } \\
\hline pT1 & 1.00 (reference) & & 1.00 (reference) & \\
\hline pT2 & $3.09(1.73-4.26)$ & $<0.001$ & $3.05(1.66-4.18)$ & 0.044 \\
\hline Tumor diameterł & $2.29(1.13-3.06)$ & 0.049 & $1.02(0.63-2.19)$ & 0.264 \\
\hline \multicolumn{5}{|c|}{ Lymphovascular invasion } \\
\hline Negative & 1.00 (reference) & & & \\
\hline Positive & $3.32(1.68-5.42)$ & $<0.001$ & $1.27(0.73-1.98)$ & 0.063 \\
\hline \multicolumn{5}{|l|}{ Differentiation } \\
\hline Well & 1.00 (reference) & & & \\
\hline Moderate & $1.07(0.51-2.44)$ & 0.752 & & \\
\hline Poor & $2.55(1.72-3.78)$ & $<0.001$ & $2.43(0.96-4.27)$ & 0.062 \\
\hline \multicolumn{5}{|l|}{ Post-TEM treatment } \\
\hline Adjuvant treatment & 1.00 (reference) & & & \\
\hline TME & $1.35(0.43-4.18)$ & 0.712 & & \\
\hline
\end{tabular}

$T M E$, total mesorectal excision; TEM, Transanal Endoscopic Microsurgery.

t.Variables were entered the multivariable analysis if a $p$ value less than 0.1 in the univariable analysis

¥.Continuous variable, $\beta$ coefficient (age) $=+0.014, \beta$ coefficient (tumor diameter) $=+0.020$

Table 4 Comparison of EORTC QLQ-CR29 score 


\begin{tabular}{|c|c|c|c|}
\hline Items & $\begin{array}{l}\text { Adjuvant treatment } \\
\text { Mean }(n)\end{array}$ & $\begin{array}{l}\text { TME } \\
\text { Mean (n) }\end{array}$ & $p$ value \\
\hline \multicolumn{4}{|l|}{ Functional scalest } \\
\hline Anxiety & $78.23(52)$ & 77.64(53) & 0.770 \\
\hline Body image & $87.35(52)$ & $88.97(53)$ & 0.607 \\
\hline Weight & $86.44(52)$ & $89.42(53)$ & 0.179 \\
\hline Sexual interest(female)§ & 25.03(23) & 19.84(19) & 0.066 \\
\hline Sexual interest(male)§ & 44.68(29) & $45.29(34)$ & 0.921 \\
\hline \multicolumn{4}{|l|}{ Symptom scales $\ddagger$} \\
\hline Urinary incontinence & $9.01(52)$ & $6.79(53)$ & 0.374 \\
\hline Urinary frequency & $18.12(52)$ & 19.34(53) & 0.576 \\
\hline Stool frequency & $25.85(52)$ & $19.73(53)$ & 0.096 \\
\hline Taste & 7.91(52) & $1.73(53)$ & $<0.001$ \\
\hline Faecal incontinence & $24.82(52)$ & $15.54(53)$ & 0.054 \\
\hline Sore skin & 19.77(52) & $16.90(53)$ & 0.776 \\
\hline Embarrassment & $18.24(52)$ & $13.31(53)$ & 0.138 \\
\hline Buttock pain & $4.67(52)$ & $17.99(53)$ & 0.030 \\
\hline Bloating & $22.21(52)$ & $13.98(53)$ & 0.126 \\
\hline Dry mouth & $10.23(52)$ & $12.24(53)$ & 0.753 \\
\hline Hair loss & $4.22(52)$ & $2.97(53)$ & 0.076 \\
\hline Embarrassment & $18.25(52)$ & $13.37(53)$ & 0.552 \\
\hline Flatulence & $42.45(52)$ & $47.97(53)$ & 0.814 \\
\hline Blood and mucus in stool & $4.41(52)$ & $3.24(53)$ & 0.575 \\
\hline Dyspareunia(female)§ & $7.15(23)$ & $10.65(19)$ & 0.532 \\
\hline Impotence(male)§ & $40.23(29)$ & $33.67(34)$ & 0.096 \\
\hline
\end{tabular}

EORTC QLQ-CR29, European Organization for Research and Treatment of Cancer Quality of Life of the colorectal cancer specific module (primary data has been transformed into score ranging from 0-100) †Higher score for functional items represents better function ‡ Higher score for functional items represents more serious symptoms 
$\S$ Gender specified

Table 5 Comparison of LARS and Wexner score 


\begin{tabular}{|c|c|c|c|}
\hline Items & $\begin{array}{l}\text { Adjuvant treatment } \\
(\mathrm{n}=52)\end{array}$ & $\begin{array}{l}\text { TME } \\
(n=53)\end{array}$ & $p$ value \\
\hline Incontinence of liquid stools & & & 0.062 \\
\hline$\geq$ Once per week & 12 & 23 & \\
\hline$<$ Once per week & 20 & 12 & \\
\hline Never & 20 & 18 & \\
\hline Incontinence of flatus & & & 0.532 \\
\hline$\geq$ Once per week & 10 & 12 & \\
\hline$<$ Once per week & 10 & 14 & \\
\hline Never & 32 & 27 & \\
\hline Clustering of stools & & & 0.092 \\
\hline$\geq$ Once per week & 13 & 24 & \\
\hline$<$ Once per week & 17 & 12 & \\
\hline Never & 22 & 17 & \\
\hline Urgency & & & $<0.001$ \\
\hline$\geq$ Once per week & 3 & 30 & \\
\hline$<$ Once per week & 18 & 10 & \\
\hline Never & 31 & 13 & \\
\hline Bowel frequency & & & 0.016 \\
\hline$>7$ times per day & 3 & 7 & \\
\hline 4-7 times per day & 6 & 12 & \\
\hline 1-3 times per day & 20 & 25 & \\
\hline$<1$ time per day & 23 & 9 & \\
\hline Severity of LARSt, n (\%) & & & 0.039 \\
\hline No & $32(57.69)$ & $23(43.40)$ & \\
\hline Minor & $11(25.00)$ & $10(18.87)$ & \\
\hline Major & $9(17.31)$ & $20(37.74)$ & \\
\hline Total LARS score & $21.67 \pm 4.232$ & $32.35 \pm 5.675$ & 0.040 \\
\hline Total Wexner score & $2.21 \pm 0.215$ & $3.73 \pm 0.464$ & 0.173 \\
\hline
\end{tabular}


LARS, low anterior syndrome; Scores 0 to 20 (no LARS), 21 to 29 (minor LARS), 30 to 42 (major LARS)

Table 6 Comparison the results of International Index of Erectile Function (IIEF-5) score for male patients.

\begin{tabular}{|llll|}
\hline Items & $\begin{array}{l}\text { Adjuvant treatment } \\
(\mathrm{n}=29)\end{array}$ & $\begin{array}{l}\text { TME } \\
(\mathrm{n}=34)\end{array}$ & p value \\
\hline Preoperative IIEF-5 score $^{\dagger}$ & $23.1 \pm 3.265$ & $21.9 \pm 2.975$ & 0.458 \\
\hline Total IIEF-5 score $^{\dagger}$ & $21.6 \pm 2.312$ & $18.7 \pm 1.379$ & 0.317 \\
\hline Grade of ED, $\mathrm{n}(\%)^{\ddagger}$ & & & 0.240 \\
\hline No & $14(48.28)$ & $12(35.29)$ & \\
\hline Mild & $5(17.24)$ & $6(17.65)$ & \\
\hline Mild to Moderate & $4(13.79)$ & $12(35.29)$ & \\
\hline Moderate & $5(17.24)$ & $2(5.88)$ & \\
\hline Severe & $1(3.45)$ & $2(5.88)$ & \\
\hline
\end{tabular}

Values in parentheses are percentages except for extra indications. $T M E$, total mesorectal excision. $E D$, Erectile Dysfunction.

Scores 5 to 7 (Severe), 8 to 11 (moderate), 12 to 16 (mild to moderate), 17 to 21 (mild) and less than 5 (No dysfunction).

†. Mann-Whitney U test;

‡. $₫ 2$ test.

\section{Figures}




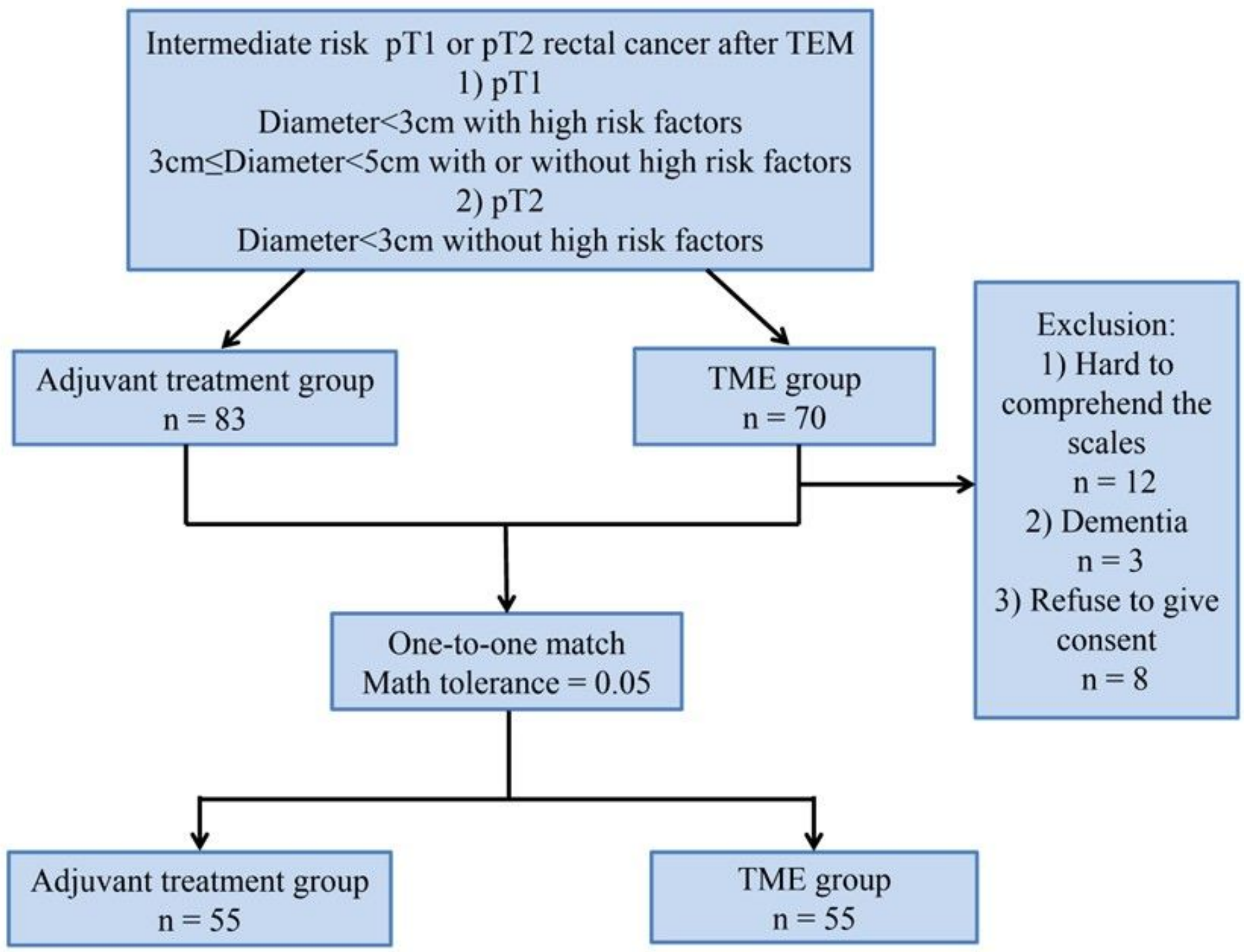

Figure 1

Inclusion flow chart of enrolled patients. 110 intermediate pathologically risk patients ( 55 patients each group) were enrolled in this study using one-to-one matching method (Math tolerance $=0.05$ ). 23 patients were excluded from the study due to unsatisfied comprehension of scales, dementia and refusal consent respectively. 

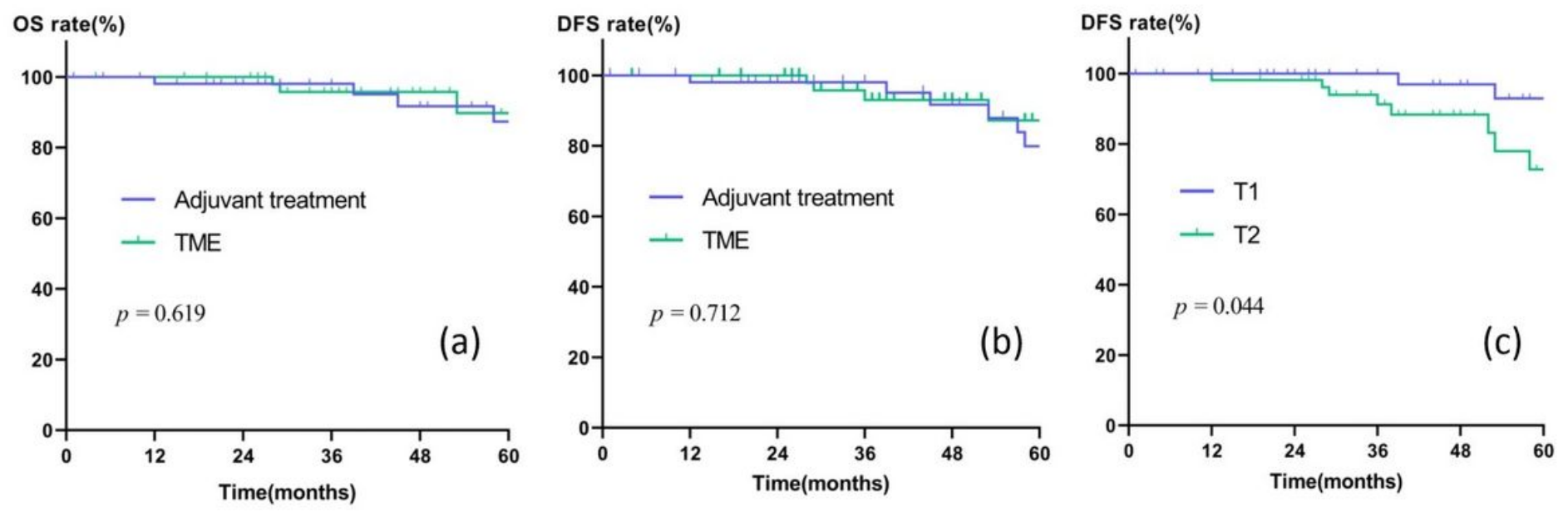

\section{Figure 2}

Survival analyses on enrolled patients. Overall survival (OS) rate comparison between the two groups

(Figure2a). No significant difference was obtained between the groups $(p=0.619)$. Disease-free survival (DFS) rate comparison between the two groups (Figure2b). No significant difference was obtained between the groups $(p=0.712)$. Pathologically stage T2 was the independent risk factors for 5 -year DFS $(p=0.044)$. Survival analyses on patients (OS and DFS). (a) OS comparison adjuvant treatment vs. TME.

(b) DFS comparison adjuvant treatment vs. TME. (c) DFS comparison pT1 vs. pT2. 


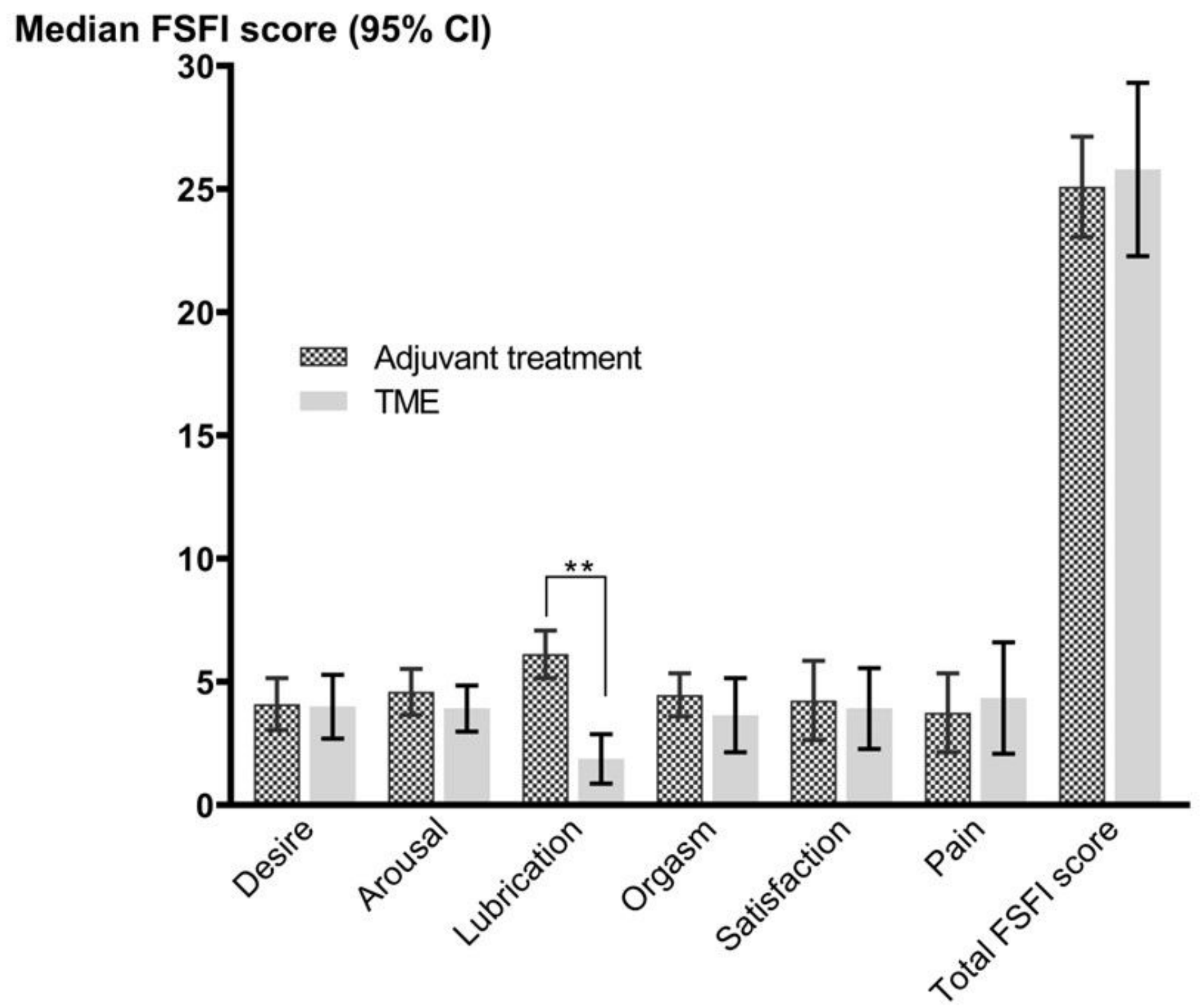

Figure 3

FSFI score comparison between two groups Adjuvant treatment group showed a better feedback on the domain of vaginal lubrication with significant difference $(p<0.001)$. Other aspects in FSFI questionnaires were in the absence of significant difference. Comparison of FSFI score and domains ( ${ }^{* \star}$. $\left.p<0.001\right)$ 